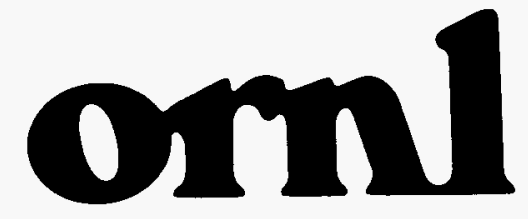

OAK RIDGE

NATIONAL

LABORATORY

MARTHN MARIETRA

\section{DECERED \\ FEด 21 1 \\ 0 STI}

Heteroscedasticity Generated by Errors in Predictors

\author{
Darryl J. Downing \\ Valerii V. Fedorov \\ Randy K. Nanstad
}

MARTIN MARIETTA ENERGY SYSTEMS, INC.

FOR THE UNITED STATES

DEPARTMENT OF ENERGY 
This report has been reproduced directly from the best available copy.

Available to DOE and DOE contractors from the Office of Scientific and Technical Information, P.O. Box 62, Oak Ridge, TN 37831; prices available from (615) 576-8401, FTS 626-8401.

Available to the public from the National Technical Information Service, U.S. Department of Commerce, 5285 Port Royal Rd., Springfield, VA 22161.

This report was prepared as an account of work sponsored by an agency of the United States Government. Neither the United States Government nor any agency thereof, nor any of their employees, makes any warranty, express or implied, or assumes any legal liability or responsibility for the accuracy, completeness, or usefulness of any information, apparatus, product, or process disclosed, or represents that its use would not infringe privately owned rights. Reference herein to any specific commercial product, process, or service by trade name, trademark, manufacturer, or otherwise, doss not necessarily consthtute or imply its endorsement, recommendation, or favoring by the United States Government or any agency thereof. The views and opinions of authors expressed herein do not necessarily state or reflect those of the United States Government or any agency thereof. 
ORNL/TM -13140

Computer Science and Mathematics Division

Mathematical Sciences Section

\title{
HETEROSCEDASTICITY GENERATED BY ERRORS IN PREDICTORS
}

\author{
Darryl J. Downing ${ }^{a}$ \\ Valerii V. Fedorov ${ }^{a}$ \\ Randy K. Nanstad ${ }^{b}$
}

- Mathematical Sciences Section

Computer Science and Mathematics Division

Oak Ridge National Laboratory

P. O. Box 2008

Oak Ridge, Tennessee 37831-6367

- Metals and Ceramics Division

Oak Ridge National Laboratory

P. O. Box 2008

Oak Ridge, Tennessee 37831-6151

Date Published: November 1995

Research sponsored by the Laboratory Directed Research and Development Program of Oak Ridge National Laboratory

\author{
Prepared by the \\ Oak Ridge National Laboratory \\ Oak Ridge, Tennessee 37831 \\ managed by \\ Lockheed Martin, Inc. \\ for the \\ U.S. DEPARTMENT OF ENERGY \\ under Contract No. DE-AC05-84OR21400
}





\section{Contents}

1 Introduction . . . . . . . . . . . . . . . 1

2 Original regression problem $\ldots \ldots \ldots \ldots \ldots \ldots \ldots \ldots$

3 Errors in predictors . . . . . . . . . . . . . . 3

4 Estimation method $\ldots \ldots \ldots \ldots \ldots \ldots \ldots \ldots \ldots \ldots$

5 Unknown $\sigma$ and $\delta \ldots \ldots \ldots \ldots \ldots \ldots \ldots \ldots \ldots \ldots$

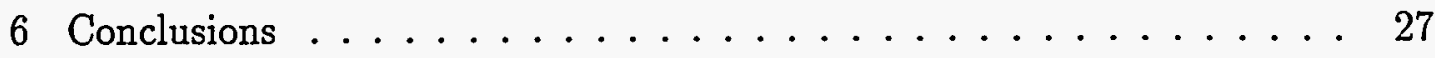

7 References . . . . . . . . . . . . . . . . . 29 
1 


\section{List of Figures}

1 Response function for the 72W irradiated data from DHN 1990. . 4

2 Response function for the 72W unirradiated data from DHN 1990. 5

3 Response function for the 73W irradiated data from DHN 1990. . 6

4 Response function for the 73W unirradiated data from DHN 1990. 7

5 Response function for the $72 \mathrm{~W}$ irradiated data. Calculated with and without adjusting for error in temperature. . . . . . . 13

6 Response function for the $72 \mathrm{~W}$ unirradiated data. Calculated with and without adjusting for error in temperature. . . . . . . 14

7 Response function for the $73 \mathrm{~W}$ irradiated data. Calculated with and without adjusting for error in temperature. . . . . . . 15

8 Response function for the $73 \mathrm{~W}$ unirradiated data. Calculated with and without adjusting for error in temperature. . . . . . 16

$9 \quad$ Standardized residuals for the $72 \mathrm{~W}$ irradiated data. Not adjusted for error in temperature. . . . . . . . . . . . . . . 19

10 Standardized residuals for the $72 \mathrm{~W}$ irradiated data. Adjusting for error in temperature. . . . . . . . . . . . . . 20

11 Standardized residuals for the $72 \mathrm{~W}$ unirradiated data. Not adjusted for error in temperature. . . . . . . . . . . . . 21

12 Standardized residuals for the $72 \mathrm{~W}$ unirradiated data. Adjusting for error in temperature. . . . . . . . . . . . . . . . 22

13 Standardized residuals for the $73 \mathrm{~W}$ irradiated data. Not adjusted for error in temperature. . . . . . . . . . . . . . . 23

14 Standardized residuals for the $73 \mathrm{~W}$ irradiated data. Adjusting for error in temperature. . . . . . . . . . . . . . . . . 24

15 Standardized residuals for $73 \mathrm{~W}$ unirradiated data. Not adjusted for error in temperature. . . . . . . . . . . . . 25

16 Standardized residuals for the 73W unirradiated data. Adjusting for error in temperature. . . . . . . . . . . . . 26 


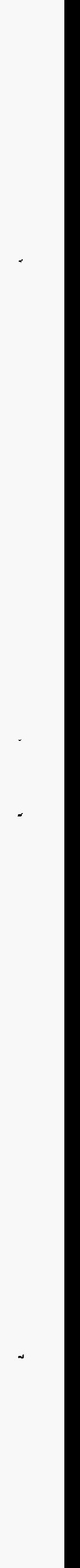




\title{
HETEROSCEDASTICITY GENERATED BY ERRORS IN PREDICTORS
}

\author{
Darryl J. Downing \\ Valerii V. Fedorov \\ Randy K. Nanstad
}

\begin{abstract}
The heteroscedasticity or changing variance observed in "raw" data may be the result of randomness or uncertainty in the predictor variables. As an example we consider "Charpy Test" experiments widely used to characterize the ductile-brittle toughness of steels such as those used for nuclear pressure vessels. While this type of experiment is of interest in itself, our main objective is to show that the use of a proper statistical technique may help to avoid the use of more complicated physical models to explain the heteroscedasticity of the observations. We also extend the existing method of regression analysis with errors in controllable variables to the case when the variances of the response and the controllable variables are both unknown.

Key words: Predictors subject to errors, regression analysis, errors in controllable variables, iterated estimators, logistic response model.
\end{abstract}


1 


\section{Introduction}

This short study was essentially motivated by results reported by Downing, Haggag, and Nanstad , 1990 or in the sequel DHN, 1990, for brevity. They were interested in the analysis of experiments related to the fracture toughness of commercial nuclear light water reactor pressure vessels. One of the tests conducted for toughness determination is the "Charpy" impact test. The tests were conducted over a range of temperatures and the impact energy required to break either irradiated or unirradiated specimens was measured and then modeled as a function of temperature.

In Section 2 we briefly discuss the model used by DHN, 1990 and the results of their statistical analyses. The basic statistical model that includes possible errors in the controllable variables is formulated and discussed in Section 3. Section 4 is based on the approach developed by one of the authors. In Section 5 a more general technique is developed and then applied to the case-study example.

\section{Original regression problem}

In what follows we accept the basic physical ideas used by DHN, 1990. For obvious reasons the same data sets will be used to make the results comparable.

DHN, 1990, fit the following model

$$
y_{i}=\eta\left(t_{i}, \theta\right)+\sigma \epsilon_{i}, \quad i=1, \ldots, k
$$

where

$y_{i}$ is the natural logarithm of energy absorbed at test,

$\eta\left(t_{i}, \theta\right)$ is a given function,

$\theta$ are unknown parameters, 
$\epsilon_{i}$ are standardized random variables (errors of observations) with the density function

$$
p\left(\epsilon_{i}\right)=\exp \left(\epsilon_{i}-\exp \epsilon_{i}\right)
$$

which is widely used in reliability analysis to describe the distribution of extrema. The parameter $\sigma$ is usually unknown. In DHN, 1990, the response function $\eta\left(t_{i}, \theta\right)$ was approximated by a fourth degree polynomial. Using a fourth degree polynomial in temperature over the range from -100 to $100 \mathrm{C}$ may lead to unstable estimation. Therefore in this study our analysis is based on the logistic response function:

$$
\eta\left(t_{i}, \theta\right)=\ln \left[\theta_{1}+\frac{\theta_{2}}{1+\exp \left[\theta_{3}\left(t-\theta_{4}\right)\right]}\right] .
$$

This function is flexible enough and has a more "physical" interpretation than the polynomial model. Data analysis in DHN, 1990, was based on the maximum likelihood method using the error distribution given in (2). For small and moderate $\sigma$ the maximum likelihood estimators for problem (1) - (3) may be well approximated by the least squares estimators for the following regression model:

$$
y_{i}=\eta\left(t_{i}, \theta\right)+\sigma \mu+\sigma \nu_{i}
$$

where $\nu_{i}=\epsilon_{i}-\mu, \mu=E\left(\epsilon_{i}\right)=0.577$ and $\eta(t, \theta)$ is defined by (3).

Moreover, asymptotically $(n \rightarrow \infty)$ both estimators coincide. The correction term $\sigma \mu$ may be incorporated in $\theta_{1}$ and $\theta_{2}$ through the obvious transformation. Therefore, for the sake of simplicity, we will use the model

$$
y_{i}=\eta\left(t_{i}, \theta^{\prime}\right)+\sigma \nu_{i}
$$

In what follows the superscript " $"$ " will be omitted when it is not misleading.

Model (1) - (3) and subsequently (5) assumes homogeneous observational errors $(\sigma \equiv$ constant). Numerous physical models discussed in applied publications 
(see, for instance, Helm, 1995) support this assumption. The results reported in DHN, 1990, were based on this assumption.

However, one can notice from plots presented in DHN, 1990, and partly cited here (see Fig 1) that the residuals are visibly greater around the mid-point of the so-called ductile to brittle (i.e., high energy to low energy) transition temperature region in each case. In the same temperature range the variability of the response variable is also highest.

The materials in question are known to be anisotropic and heterogenous in terms of microstructural features (e.g., grain size and orientation, etc). Furthermore, in the transition temperature region, there is competition between the separate micromechanisms which lead to brittle or ductile fracture. These factors contribute to variations in measured mechanical properties. Besides those metallurgical contributions to variability, there are two other possible explanations for the observed variability of the response variable. First, it can be that the selected model is not very accurate and the "intrinsic" or "physical" variability of the observed response depends upon the temperature of a tested specimen. The second possibility is that some additional variability induced by an experimenter (or experimental system) may be an explanation of the observed phenomenon. In this paper we will try to explore the second case, suspecting that the variability may arise due to error in temperature control of the test.

\section{Errors in predictors}

Let us consider the following modification of model (5):

$$
\begin{aligned}
y_{i} & =\eta\left(t_{i}, \theta\right)+\sigma \nu_{i}, \\
t_{i} & =t_{0 i}+\delta \gamma_{i}
\end{aligned}
$$




\section{Log Energy}

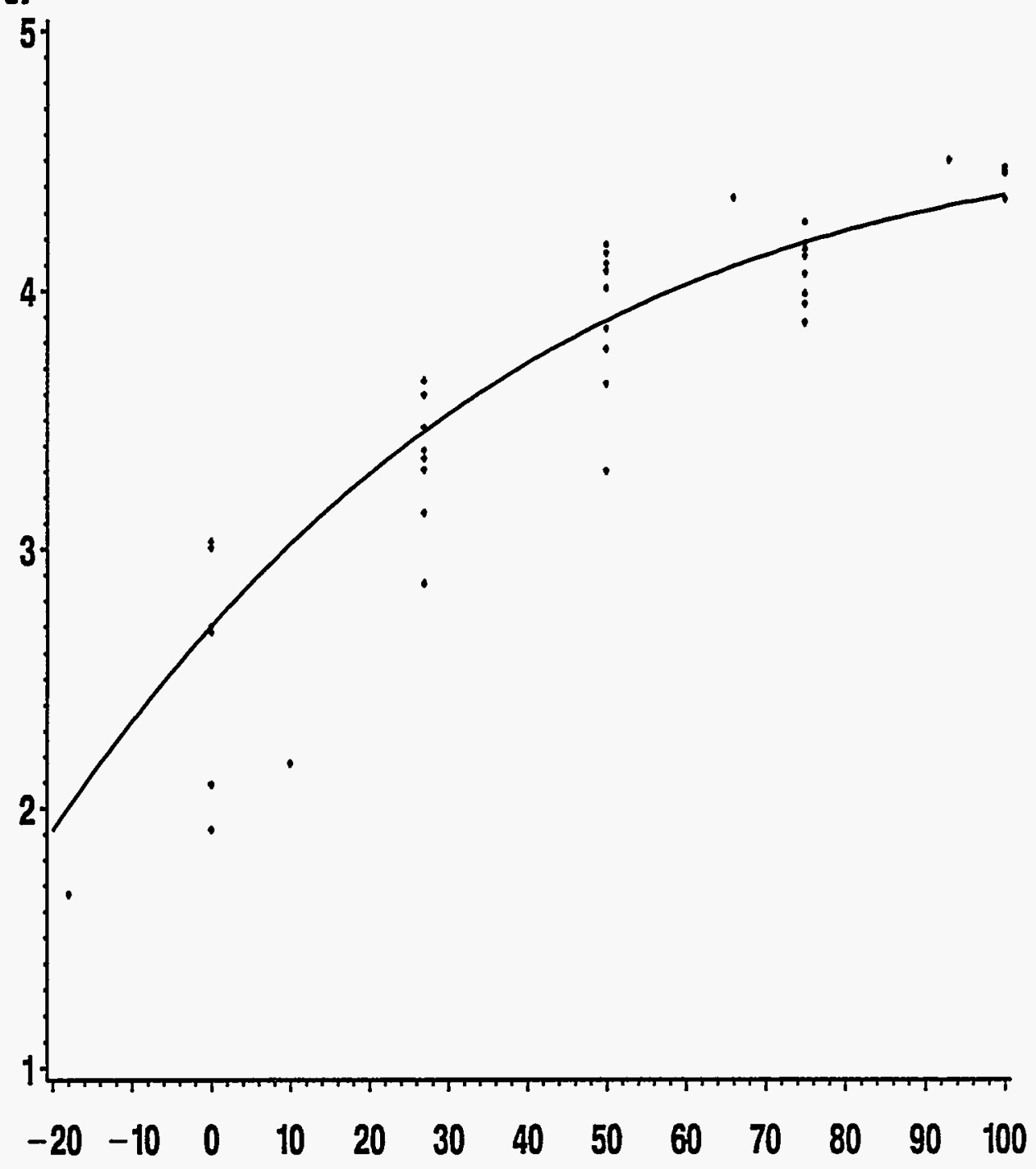

Figure 1: Response function for the 72W irradiated data from DHN 1990. 


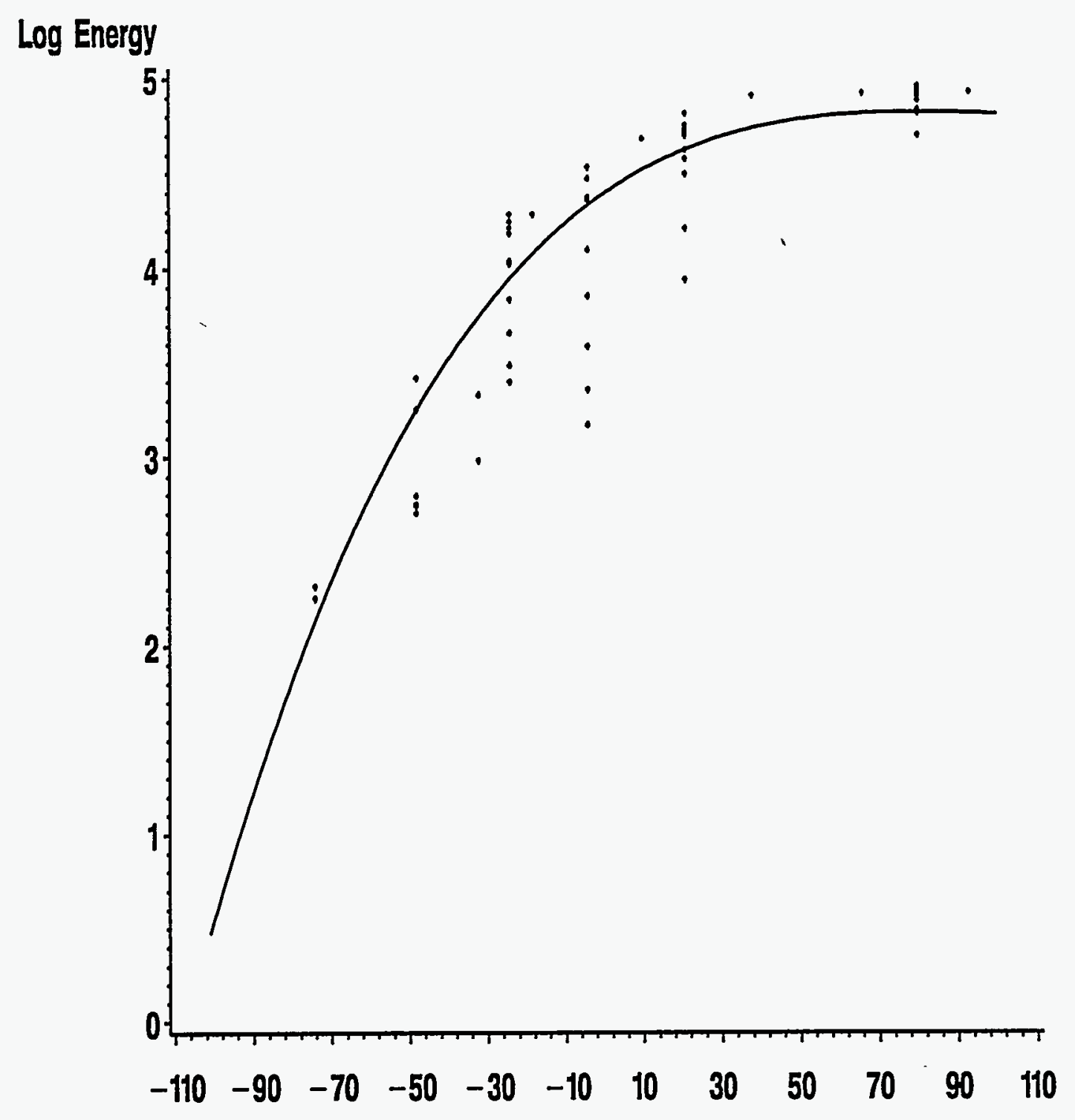

Figure 2: Response function for the 72W unirradiated data from DHN 1990. 


\section{Log Energy}

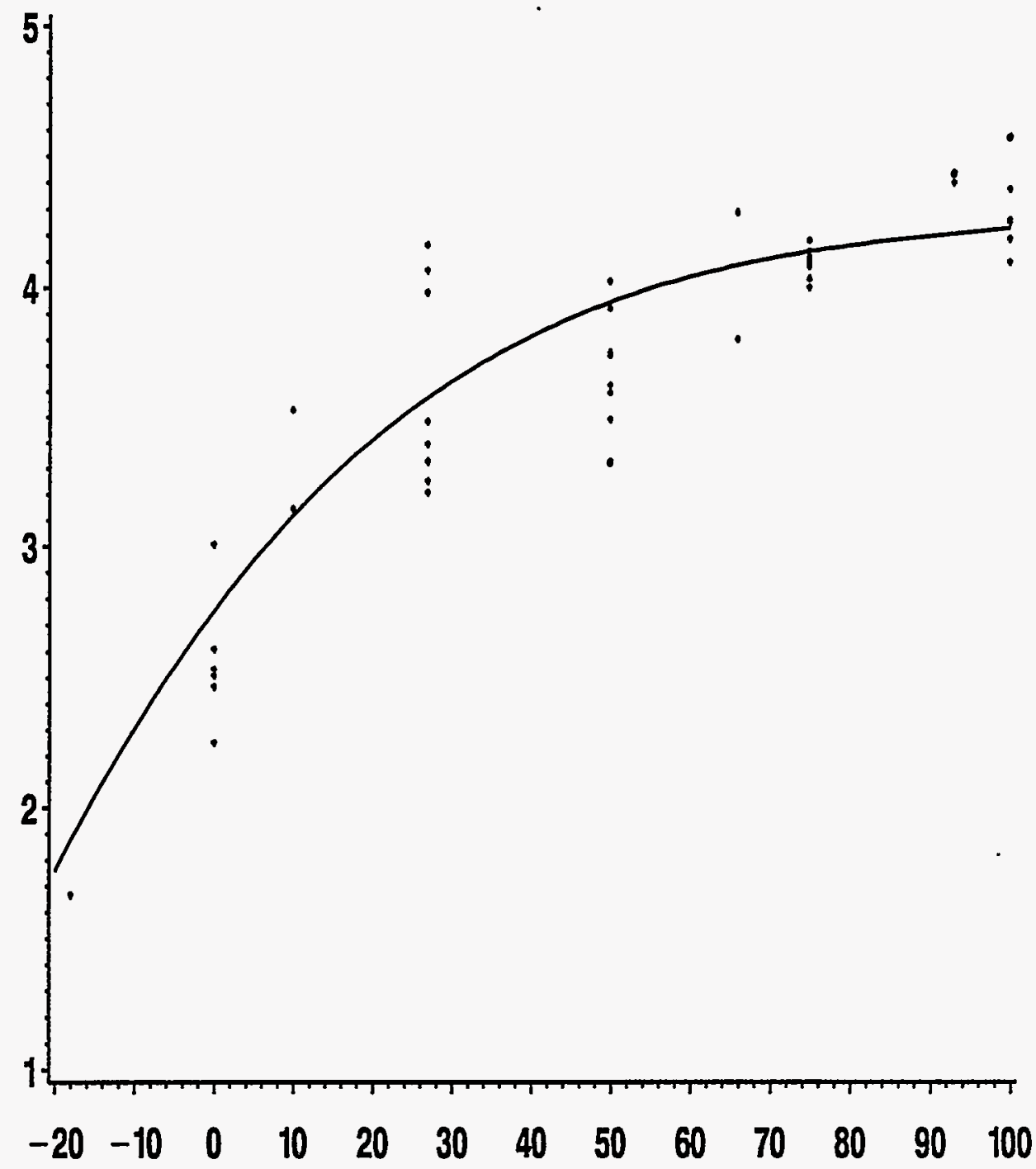

Figure 3: Response function for the 73W irradiated data from DHN 1990. 


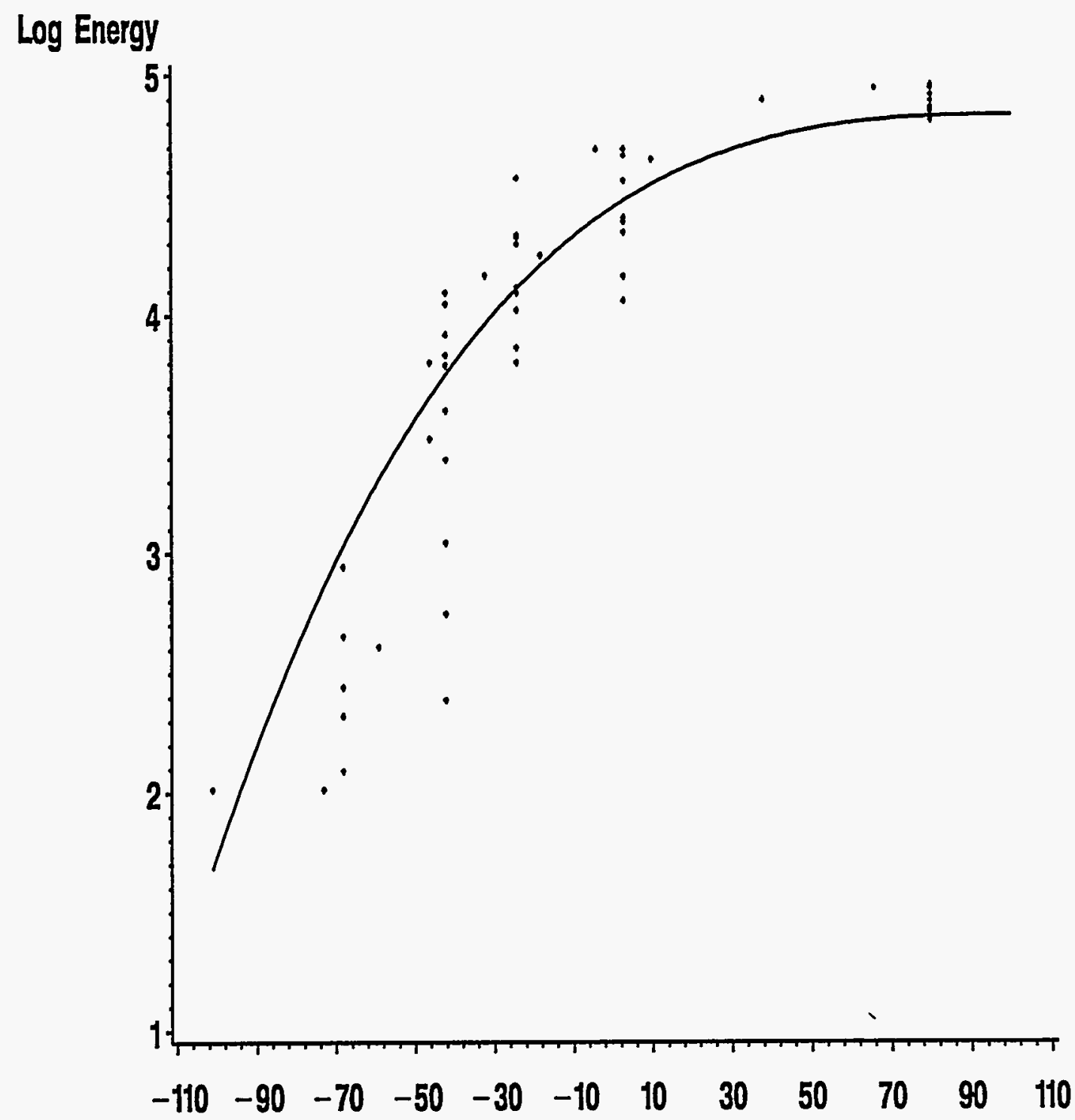

Figure 4: Response function for the 73W unirradiated data from DHN 1990. 
where $y_{i}$ and $t_{0 i}$ (the desired temperature) are known, $\nu_{i}$ and $\gamma_{i}$ are standardized random variables with zero means and unit variances. We assume that $\nu_{i}$ and $\gamma_{i}$ are independent and all random variables corresponding to different observations are independent as well. Model (6) means that an experimenter wants to test specimens at temperatures $t_{0 i}$ but cannot control those temperatures completely and therefore the actual tests take place at temperatures $t_{0 i}+\delta \gamma_{i}$. The regression problem for this model was intensively studied for quite a while. If one suspects that the shape of the probability distributions of $\nu_{i}$ and $\gamma_{i}$ may significantly influence the estimates then the conditional distribution, $\mathrm{p}\left(y_{i} \mid t_{0 i}\right)$, must be found and the maximum likelihood method can be applied (see Fuller, 1987, Ch 1.6.) For our purpose a simpler approach based on the.results by Fedorov, 1974, see also Seber and Wild, 1989, Ch 10.9, appears to be sufficient.

Let us first assume that $\sigma$ and $\delta$ are known and also that $\delta$ is "relatively" small. Assuming the existence of all the needed moments of the distribution under consideration and using Taylor's expansion of (6) with respect to $\delta$ one can show:

$$
\begin{aligned}
E\left(y_{i} \mid t_{0 i}, \theta\right) & =\eta\left(t_{0 i}, \theta\right)+\frac{1}{2} \delta^{2} \ddot{\eta}\left(t_{0 i}, \theta\right)+o\left(\delta^{2}\right), \\
\operatorname{Var}\left(y_{i} \mid t_{0 i}, \theta\right) & =\sigma^{2}+\delta^{2} \dot{\eta}^{2}\left(t_{0 i}, \theta\right)+o\left(\delta^{2}\right),
\end{aligned}
$$

where E and Var mean "expectation" and "variance" correspondingly, $\dot{\eta}$ and $\ddot{\eta}$ mean the first and second derivatives of $\eta$ with respect to $t$. From (8) it is easy to see that the "total" uncertainty in the observations have the tendency to increase in regions where the absolute value of the first derivative $\dot{\eta}(t, \theta)$ increases. This fact may explain the behavior of residuals in Fig $1 a$ and $b$. 


\section{Estimation method}

If one wants to stay within the realm of the least squares method then the estimator (the higher order terms are neglected):

$$
\theta^{*}=\operatorname{Arg} \min _{\theta \in \Omega} \sum_{i=1}^{n}\left[\frac{y_{i}-\eta\left(t_{0 i}, \theta\right)-\frac{1}{2} \delta^{2} \ddot{\eta}\left(t_{0 i}, \theta\right)}{\sigma^{2}+\delta^{2} \dot{\eta}^{2}\left(t_{0 i}, \theta\right)}\right],
$$

where $\Omega$ is the set of admissible values of $\theta$, looks very reasonable. However, in Fedorov, 1974, it was shown that generally the estimator defined by (7) is not consistent and that the following "iterated" least squares estimators should be used instead:

$$
\begin{gathered}
\hat{\theta}=\lim _{s \rightarrow \infty} \theta_{s} \\
\theta_{s}=\operatorname{Arg} \min _{\theta \in \Omega} \sum_{i=1}^{n} w_{s i}\left[y_{s i}-\eta\left(t_{0 i}, \theta\right)\right]^{2},
\end{gathered}
$$

where

$$
\begin{aligned}
w_{s i}^{-1} & =\sigma^{2}+\delta^{2} \dot{\eta}^{2}\left(t_{0 i}, \theta_{s-1}\right) \\
y_{s i} & =y_{i}-\frac{1}{2} \delta^{2} \ddot{\eta}^{2}\left(t_{0 i}, \theta_{s-1}\right) .
\end{aligned}
$$

Discussions of similar approaches (but in different statistical settings) may be found, for instance, in Charles, Frome and Yu, 1976, and Jennrich and Moore, 1975. Estimation procedure (10) assumes that a standard nonlinear least squares algorithm with weights is used repeatedly without any intrinsic changes in the algorithm itself or corresponding software.

When there exists an opportunity to develop an independent software then the following version of (10) based on the Newton-Raphson algorithm (see, for instance, Seber and Wild, 1989) looks more attractive from the computational standpoint: 


$$
\begin{aligned}
\hat{\theta} & =\lim _{s \rightarrow \infty} \theta_{s}, \\
\theta_{s} & =\theta_{s-1}+\zeta_{s} M_{s}^{-1} Y_{s}, \\
M_{s} & =\sum_{i=1}^{n} w_{s i} f_{s i} f_{s i}^{T}, \\
Y_{s} & =\sum_{i=1}^{n} w_{s i} y_{s i} f_{s i}, \\
f_{s i} & =f\left(t_{i}, \theta_{s-1}\right), \quad f(t, \theta)=\frac{\partial \eta(t, \theta)}{\partial \theta} .
\end{aligned}
$$

When $\zeta_{s} \equiv 1$, then 1 can be considered as the solution of the linearized with respect to $\theta$ version of (11). Evidently the estimators (10) and (12) are statistically identical if one manages to prove that limits of the sequences generated by (10) and (12) coincide. In practice this coincidence may be guaranteed by a proper choice of the sequence $\left\{\zeta_{s}\right\}$. For the simplest choice of $\left\{\zeta_{s}\right\}$ when $\zeta_{s} \equiv 1$ the following asymptotic result takes place (we do not pursue the mathematical rigor here).

For sufficiently smooth $\eta(x, \theta)$ as a function of $x$ and $\theta$ (and, in particular, for the logistic function considered in this paper) the probability $P_{n}$ that the limits for (10) and (12) coincide tends to one when the number of observation $n$ tends to infinity, i.e.

$$
\lim _{n \rightarrow \infty} P_{n}=1 \text {. }
$$

In other words, for relatively small sample sizes there exists an opportunity that (10) and (12) may be different when $\zeta_{s} \equiv 1$, but for larger samples the chances of that are negligible.

In the standard least squares method enforcing the monotonicity of the sequence 


$$
\nu_{s}=\sum_{i=1}^{n} w_{s i}\left(y_{s i}-\eta\left(t_{0 i}, \theta_{s-1}\right)\right)^{2}
$$

through the proper choice of $\zeta_{s}$ (compare, for instance, with Seber and Wild, 1989) usually assures the convergence of an iterative procedure.

Enforced monotonicity in the considered case may cause estimator (12) to be inconsistent (compare with Fedorov, 1974). To explain this phenomenon the reader must notice that generally it can not be stated that

$$
\min _{\theta \in \Omega} \sum_{i=1}^{n} w_{s i}\left[y_{s i}-\eta\left(t_{0 i}, \theta\right)\right]^{2}>\lim _{s \rightarrow \infty} \min _{\theta \in \Omega} \sum_{i=1}^{n} w_{s i}\left[y_{s i}-\eta_{i}\left(t_{0 i}, \theta\right)\right]^{2}
$$

Actually in practice the inverse can be observed frequently. Estimator (10) is consistent and asymptotically normally distributed in the framework of approximation (7), (8), see Fedorov, 1974. Therefore, for sufficiently large number of observations the variance-covariance of the estimated parameters approximately equals:

$$
\operatorname{Cov}\left(\theta^{*}\right) \simeq \sum_{i=1}^{n} w_{i} f\left(t_{i}, \theta^{*}\right) f^{T}\left(t_{i}, \theta^{*}\right)
$$

where $w_{i}=\lim _{s \rightarrow \infty} w_{s i}$, and $f(t, \theta)$ is defined in the comments to (12), (13).

Matrix (16) may be computed inside of a standard nonlinear least squares routine used to solve (11). One can notice also that

$$
\operatorname{Cov}\left(\theta^{*}\right)=\lim _{s \rightarrow \infty} M_{s}
$$

where the matrix $M_{s}$ is defined in comments to (12), (13).

So far, we have assumed that the standard errors $\sigma$ and $\delta$ are given. Of course, in most practical situations those parameters have to be estimated. Details on how to modify (10) to estimate $\sigma$ and $\delta$ are discussed in Section 5 . 
For the experiments analyzed in DHN, 1990, the needed standard errors can be estimated independently of (10). As a matter of fact, there are a number of points with repeated observations and some of them are allocated where the response function (see Fig. 1-4) achieves its upper limit and correspondingly the first derivative of response function vanishes. Therefore,

$$
\operatorname{Var}\left(y_{i} \mid t_{0 i}, \theta\right) \simeq \sigma^{2}
$$

and for the first stage of this study the simple estimator

$$
\begin{gathered}
\hat{\sigma}^{2}=\frac{1}{n_{i}-1} \sum_{j=1}^{n_{i}}\left(y_{i j}-\bar{y}_{i}\right)^{2}, \\
\bar{y}_{i}=\frac{1}{n_{i}} \sum_{j=1}^{n_{i}} y_{i j}
\end{gathered}
$$

was used.

The parameter $\delta$ was chosen as the accuracy of achieving the desired temperature. With a view towards analyzing a boundary situation, $\delta$ was selected to be 15C. This selection was chosen following a review of Nanstad et al. (1990), which considered the influence of various thermal conditioning on media on temperature changes experienced by the test specimen during Charpy impact testing. The value chosen and used for this study is not a value normally observed or expected. The estimation procedures (8) can be easily embedded in the standard reweighted least squares algorithm. In particular we have used the nonlinear least squares procedure with reweighting from SAS, 1990. In (8) the set $\Omega$ was defined by inequalities: $\theta_{1} \geq 0, \theta_{2} \geq 0, \theta_{3} \geq 0$. Fig. $5-8$ give a graphical presentation of the results, while Table 1 complements them with the parameter estimates and their asymptotic standard errors.

Everywhere the iterations were started with $w_{0 i}^{-1}=\hat{\sigma}^{2}$ and $y_{0 i}=y_{i}$. Therefore the results of the first iteration coincide with the least squares estimates (dotted lines). One can see that the iterated estimation does not change the response 


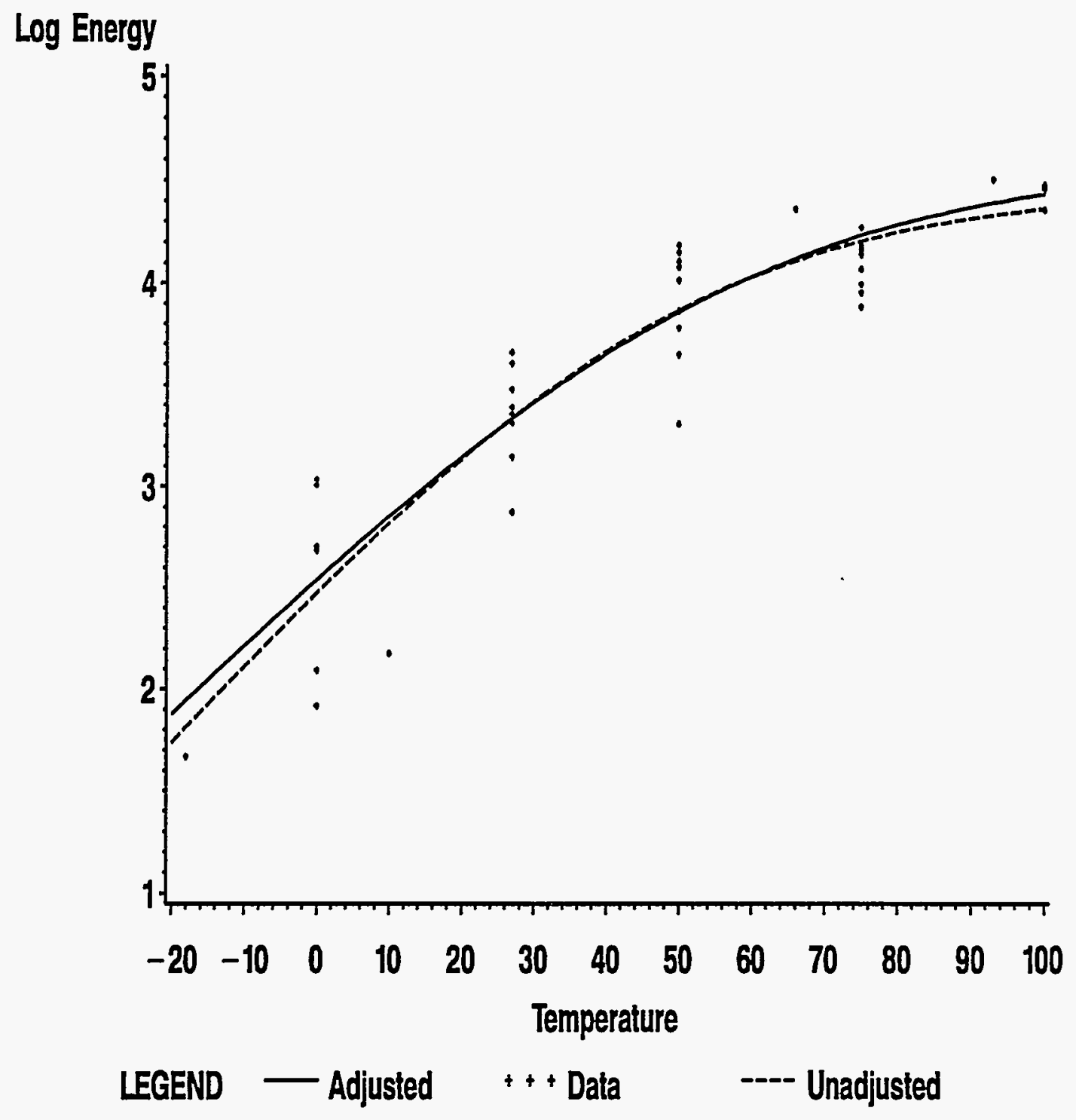

Figure 5: Response function for the $72 \mathrm{~W}$ irradiated data. Calculated with and without adjusting for error in temperature. 


\section{Log Energy}

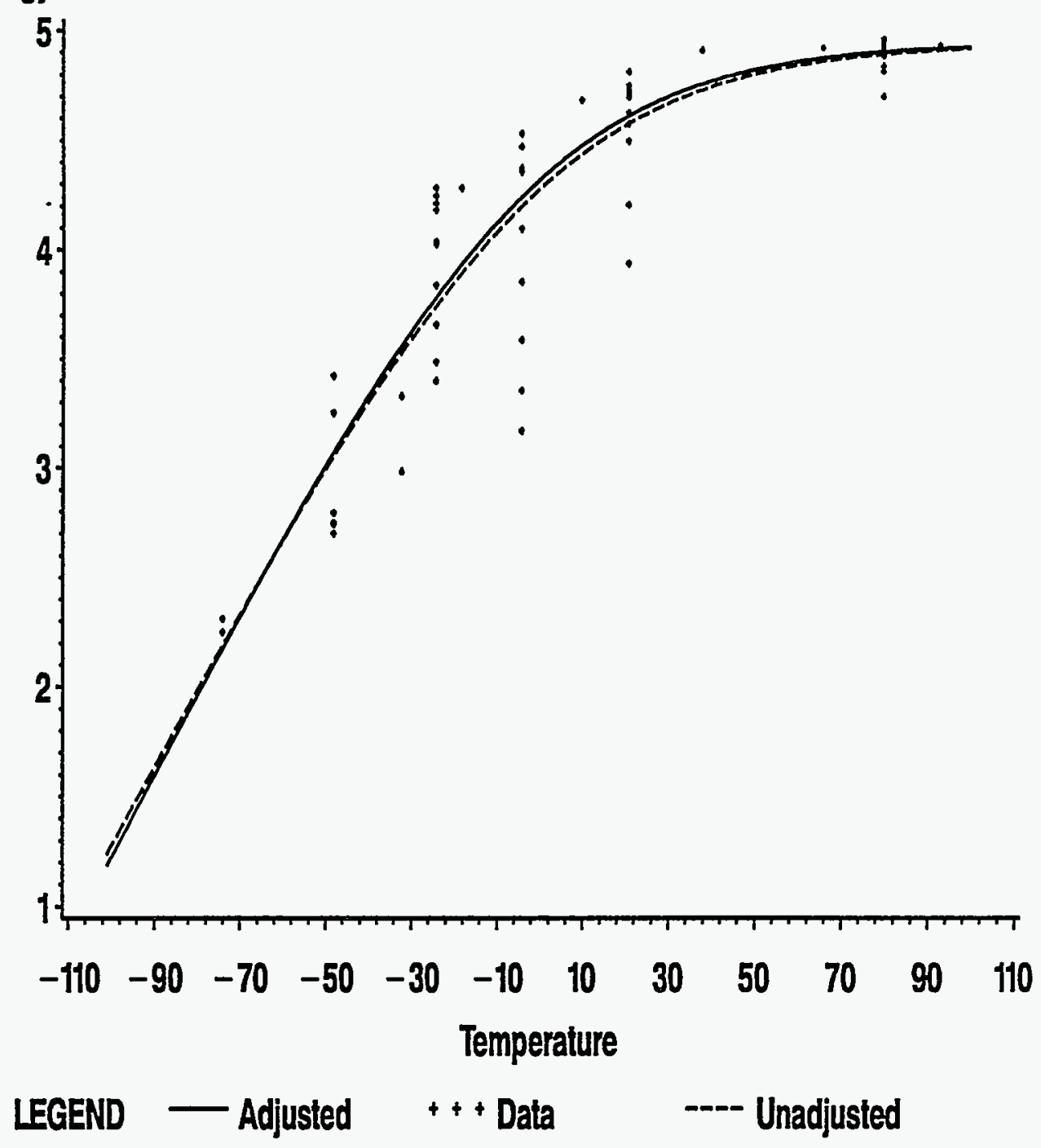

Figure 6: Response function for the $72 \mathrm{~W}$ unirradiated data. Calculated with and without adjusting for error in temperature. 


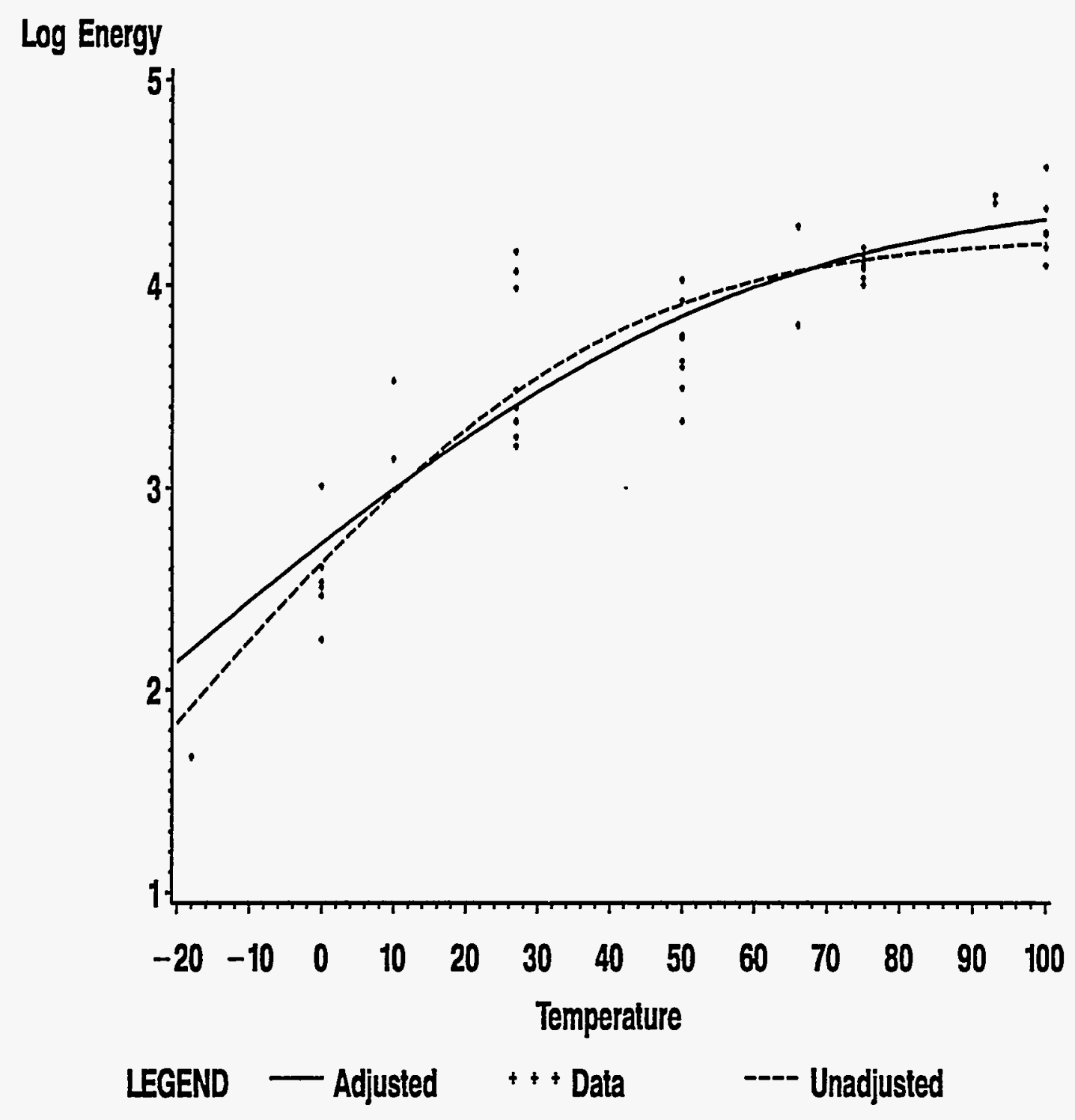

Figure 7: Response function for the 73W irradiated data. Calculated with and without adjusting for error in temperature. 


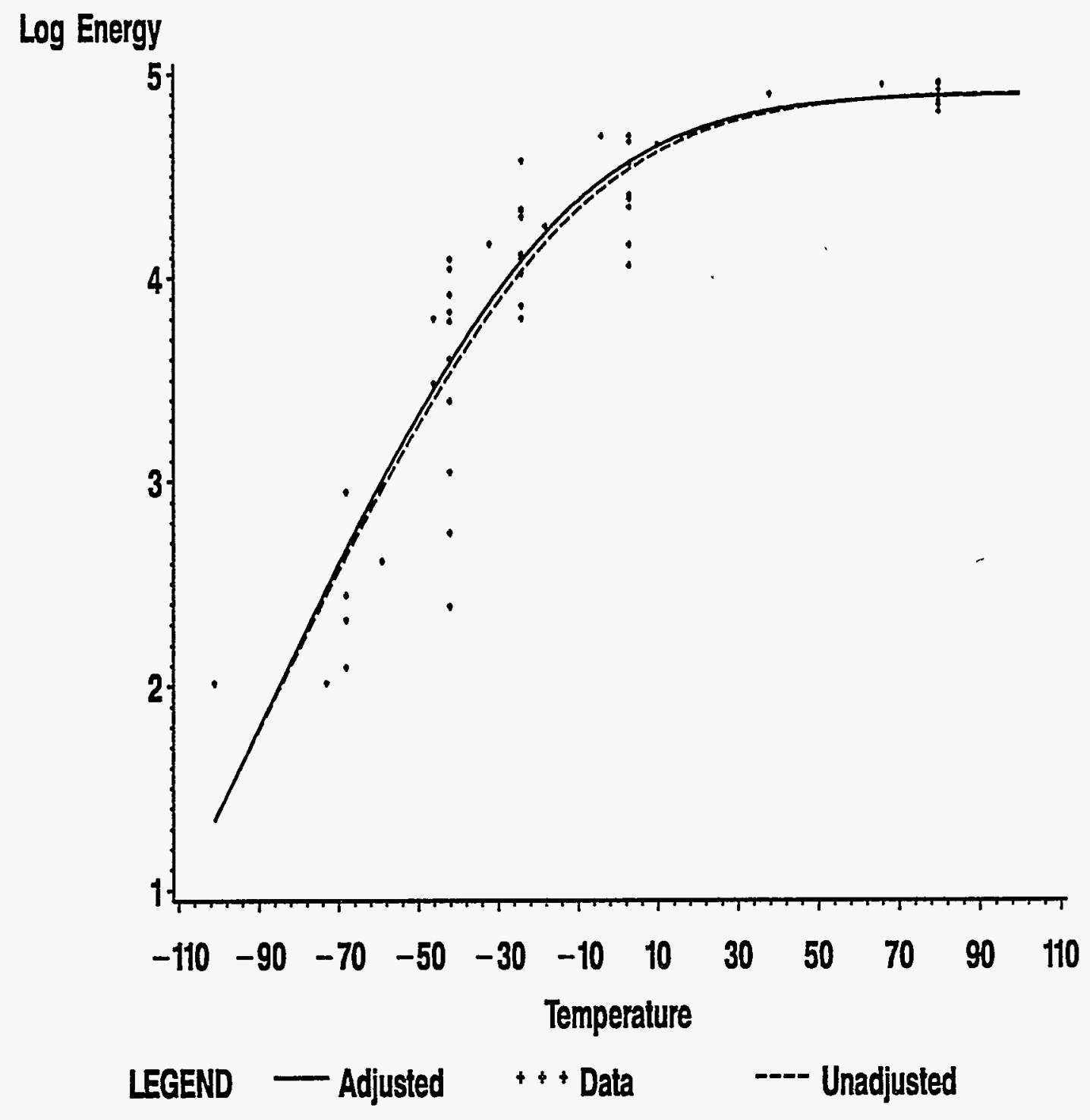

Figure 8: Response function for the $73 \mathrm{~W}$ unirradiated data. Calculated with and without adjusting for error in temperature. 


\begin{tabular}{|c|c|c|c|c|c|}
\hline \multirow[t]{2}{*}{ Dataset } & \multirow[t]{2}{*}{ Parameter } & \multicolumn{2}{|c|}{ Standard LSE } & \multicolumn{2}{|c|}{ Iterated LSE } \\
\hline & & Estimate & Standard Error & Estimate & Standard Error \\
\hline \multirow[t]{3}{*}{$72 I$} & $\mathrm{u}$ & 4.45 & 0.054 & 4.58 & 0.137 \\
\hline & $\theta_{3}$ & 0.04 & .002 & 0.04 & 0.006 \\
\hline & $\theta_{4}$ & 44.75 & 1.647 & 52.17 & 5.023 \\
\hline \multirow[t]{3}{*}{$72 U$} & $\mathrm{u}$ & 4.93 & 0.033 & 4.93 & 0.040 \\
\hline & $\theta_{3}$ & 0.04 & 0.001 & 0.04 & 0.004 \\
\hline & $\theta_{4}$ & -1.57 & 2.265 & -3.70 & 4.274 \\
\hline \multirow[t]{3}{*}{$73 I$} & $\mathrm{u}$ & 4.23 & 0.035 & 4.46 & 0.116 \\
\hline & $\theta_{3}$ & 0.05 & 0.002 & 0.03 & 0.006 \\
\hline & $\theta_{4}$ & 29.94 & 1.217 & 45.55 & 4.766 \\
\hline \multirow[t]{3}{*}{$73 \mathrm{U}$} & $\mathbf{u}$ & 4.90 & 0.030 & 4.89 & 0.033 \\
\hline & $\theta_{3}$ & 0.04 & 0.001 & 0.04 & 0.004 \\
\hline & $\theta_{4}$ & -15.98 & 2.113 & -18.60 & 4.844 \\
\hline
\end{tabular}

function too much. As expected the most significant corrections appear in areas where the second derivatives are relatively large. Evidently the least squares estimation of the response function leads to a negative bias when the second derivative is positive and to a positive bias when it is negative, compare with (7).

The values of the parameters estimates do not change significantly going from the unweighted to the weighted/iterated estimates. We would like to mention here that estimates of $\theta_{1}$ were not significantly different from 0 in all the cases and therefore this parameter was excluded from further analysis. Since $\theta_{1}$ was excluded then we may use a more convenient version of (3):

$$
\eta\left(t_{i}, \theta\right)=u-\ln \left(1+\exp \left(\theta_{3}\left(t-\theta_{4}\right)\right)\right)
$$

Note in this parameterization that $u$ has taken the place of $\ln \left(\theta_{2}\right)$ and $u$ is given in Table 1.

The most noticeable changes in the results occurred to the "accuracy" measures of the estimators. We can see than almost twofold increase in the values of the standard error estimates. Actually only the numbers reported for the last 
iteration can be considered as the asymptotic variances of the estimators. The values, which appear at the first iteration and are usually reported as the variances in the least squares method may support false expectations of a practitioner about the quality of the standard least squares estimates. In reality, the variances of the least squares estimates will be greater than the values reported in Table 1. Moreover the estimators of the parameters are not consistent due to the bias generated by (7).

We plotted the standardized residuals (see Fig. 9-16)

$$
r_{s i}=w_{s i}\left[y_{s i}-\eta\left(t_{i}, \hat{\theta}_{s}\right)\right]
$$

for $\delta=0$ and $\delta^{*}=15$, when the procedure had converged. Since the residuals fall in a horizontal band across all temperatures, one can see that for $\delta^{*}$ there is no more heteroscedasticity which is so prominent with $\delta=0$ (for the standard least squares estimators). In other words, based on a $\delta=15$ (considered a bounding value) and neglecting metallurgical factors, the methodology developed herein may explain the heteroscedasticity observed in Charpy impact populations such as those in DHN, 1990. We would like to emphasize at this point that perhaps other explanations for the heteroscedasticity of the original regression model can be found and they can be related to the change of the response function or the type of assumed distribution on the errors $\epsilon_{i}$. Our analysis tried to remove the heterscedasticity within the framework of the previously accepted "physical" model.

\section{Unknown $\sigma$ and $\delta$}

Iterative procedure (10) together with (11) leads to the results which have explained the appearance of heteroscedasticity in DHN, 1990. Nevertheless, two parameters: $\sigma$ and $\delta$ were evaluated in a rather ad hoc fashion. The whole estimation procedure will become better formalized if the iterative estimation in- 


\section{Standardized}

Residual

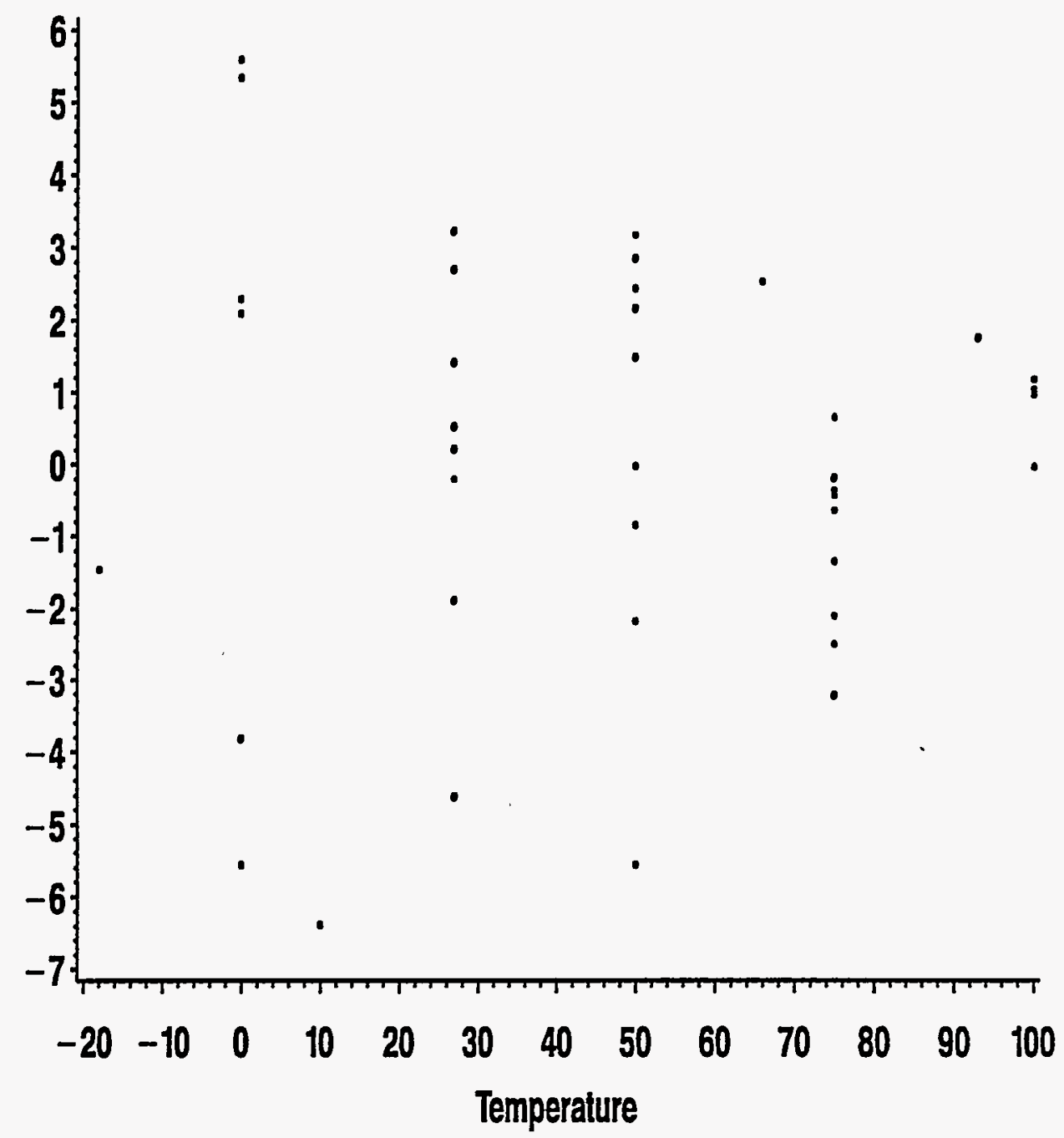

Figure 9: Standardized residuals for the $72 \mathrm{~W}$ irradiated data. Not adjusted for error in temperature. 


\section{Standardized}

Residual

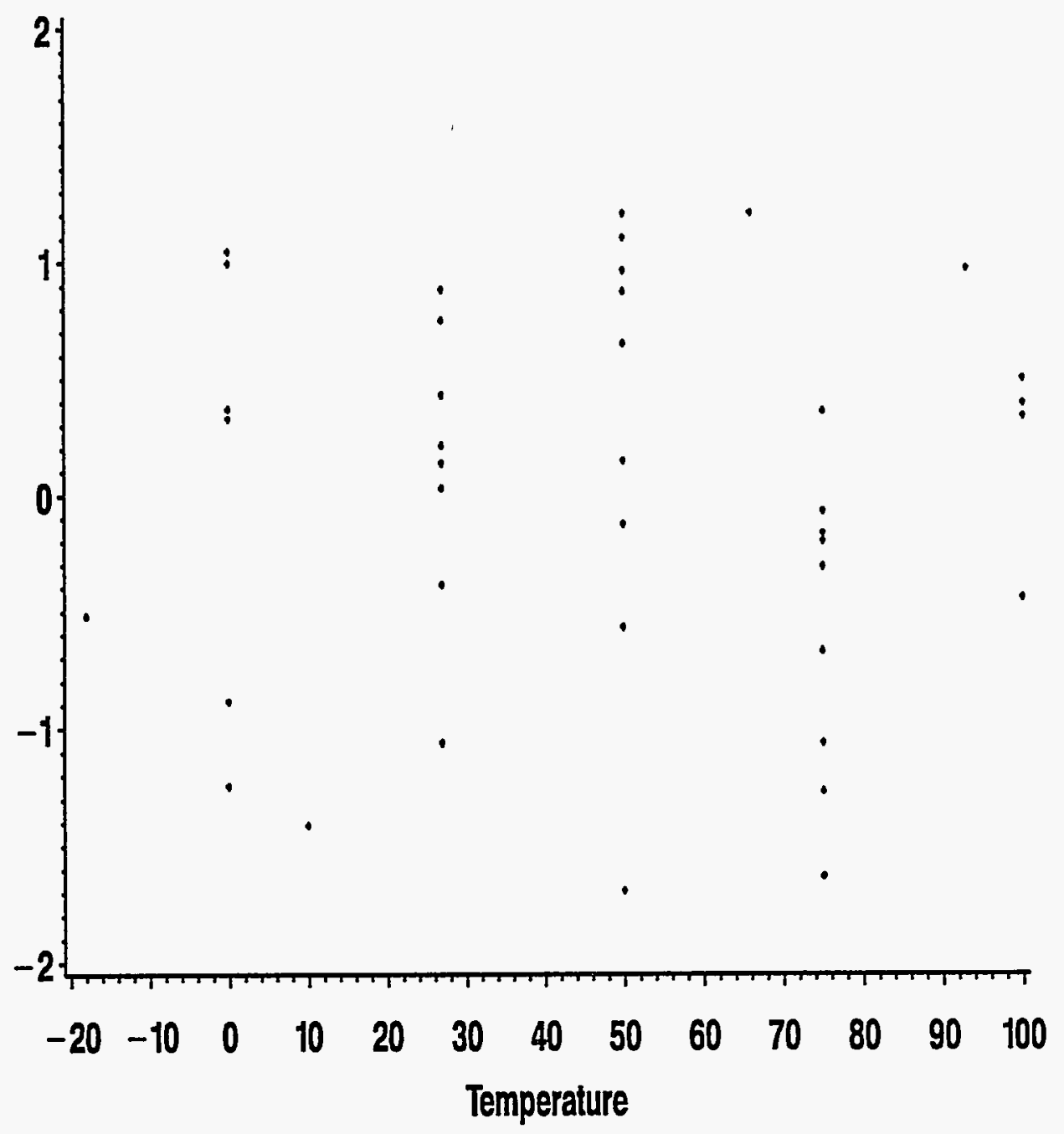

Figure 10: Standardized residuals for the $72 \mathrm{~W}$ irradiated data. Adjusting for error in temperature. 


\section{Standardized}

Residual

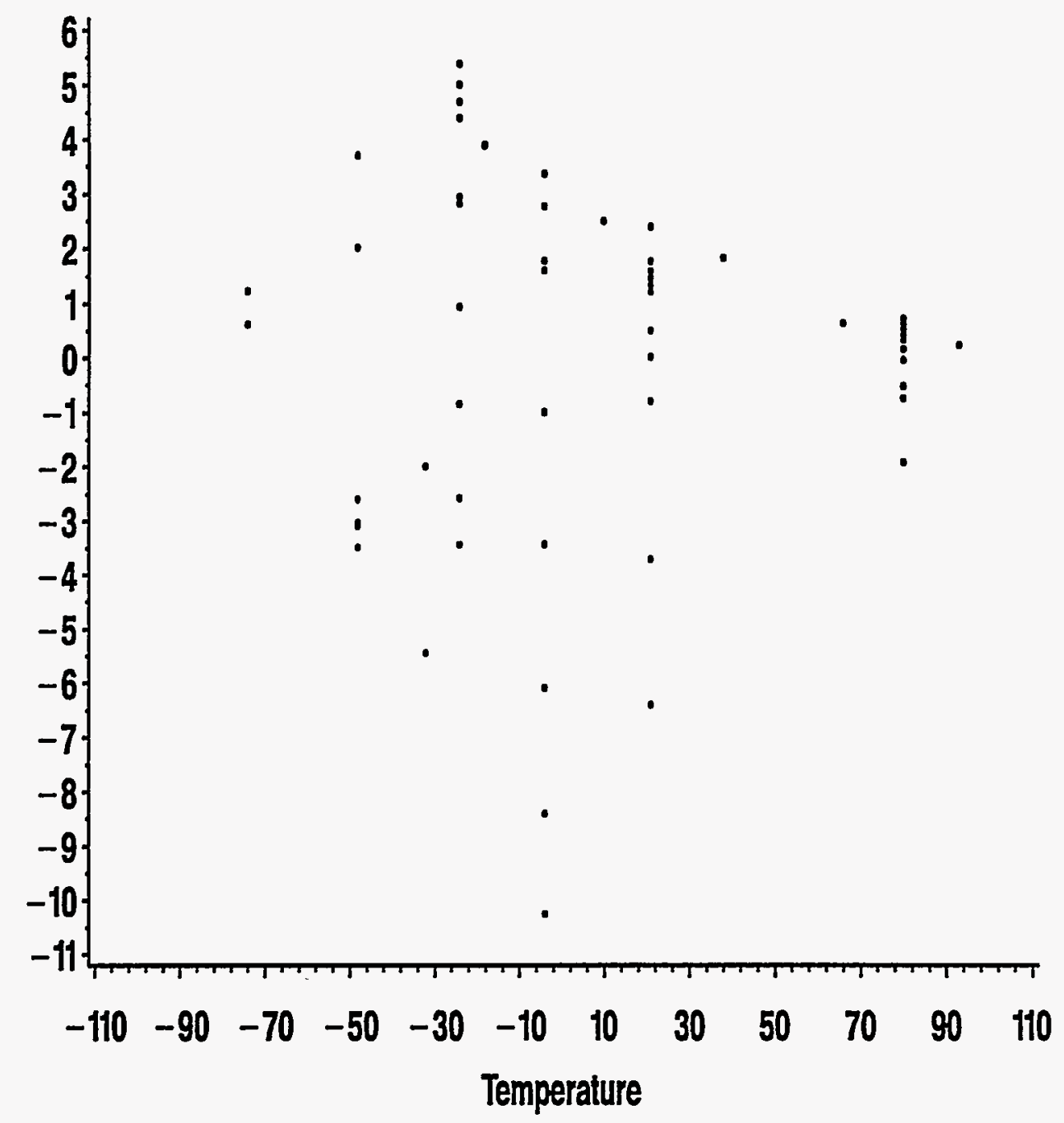

Figure 11: Standardized residuals for the $72 \mathrm{~W}$ unirradiated data. Not adjusted for error in temperature. 


\section{Standardized}

Residual

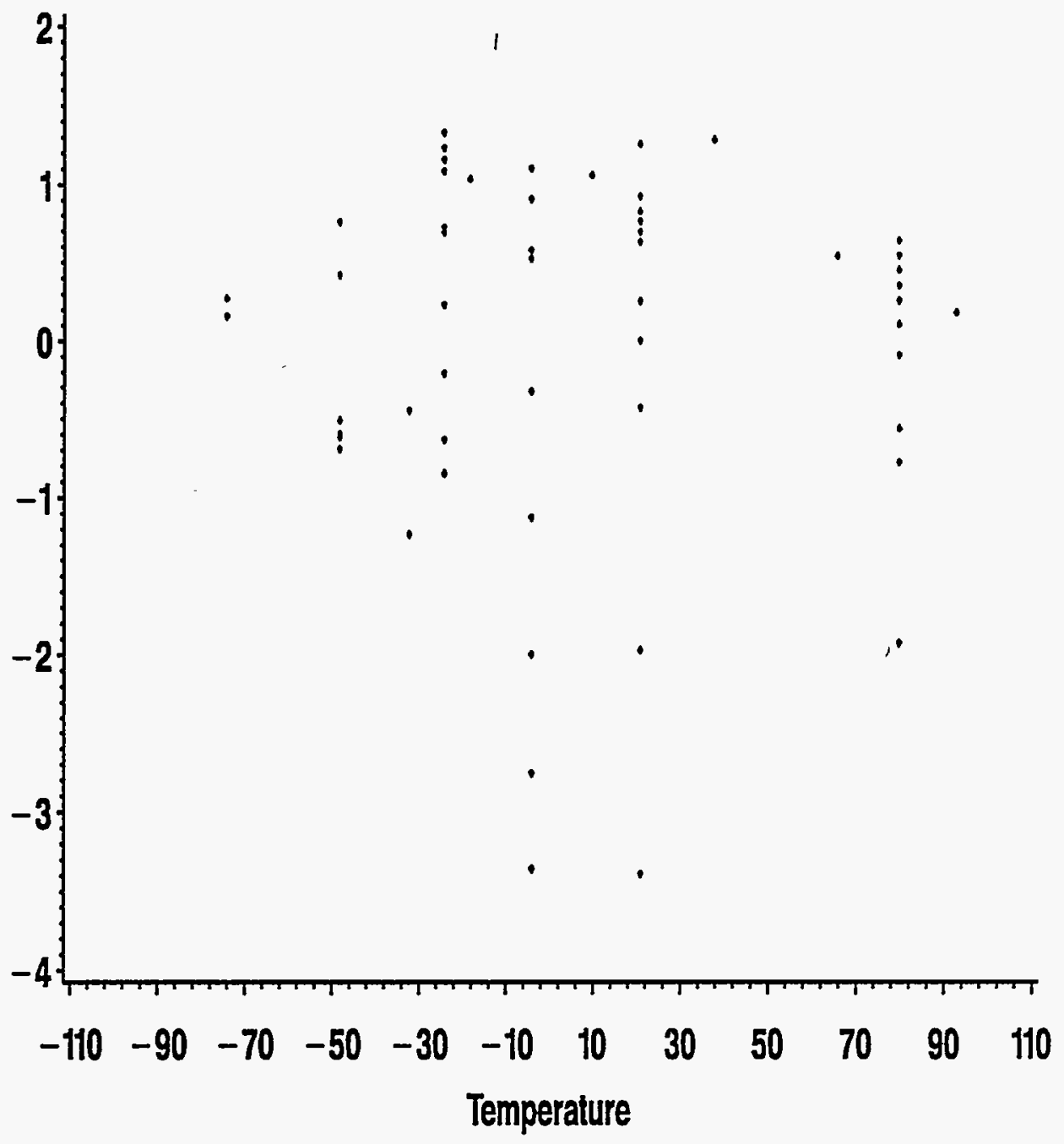

Figure 12: Standardized residuals for the $72 \mathrm{~W}$ unirradiated data. Adjusting for error in temperature. 


\section{Standardized}

Residual

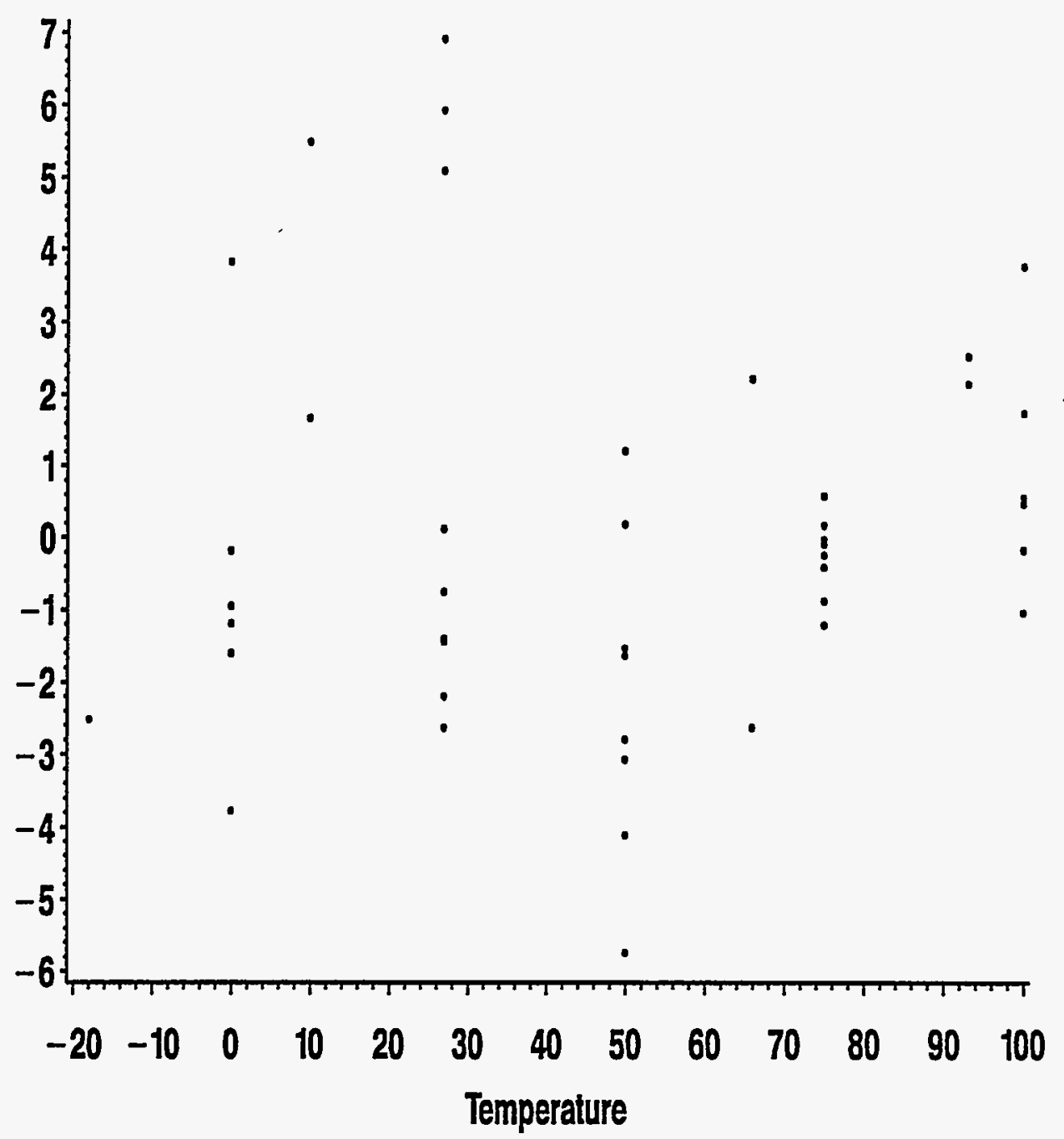

Figure 13: Standardized residuals for the $73 \mathrm{~W}$ irradiated data. Not adjusted for error in temperature. 


\section{Standardized}

Residual

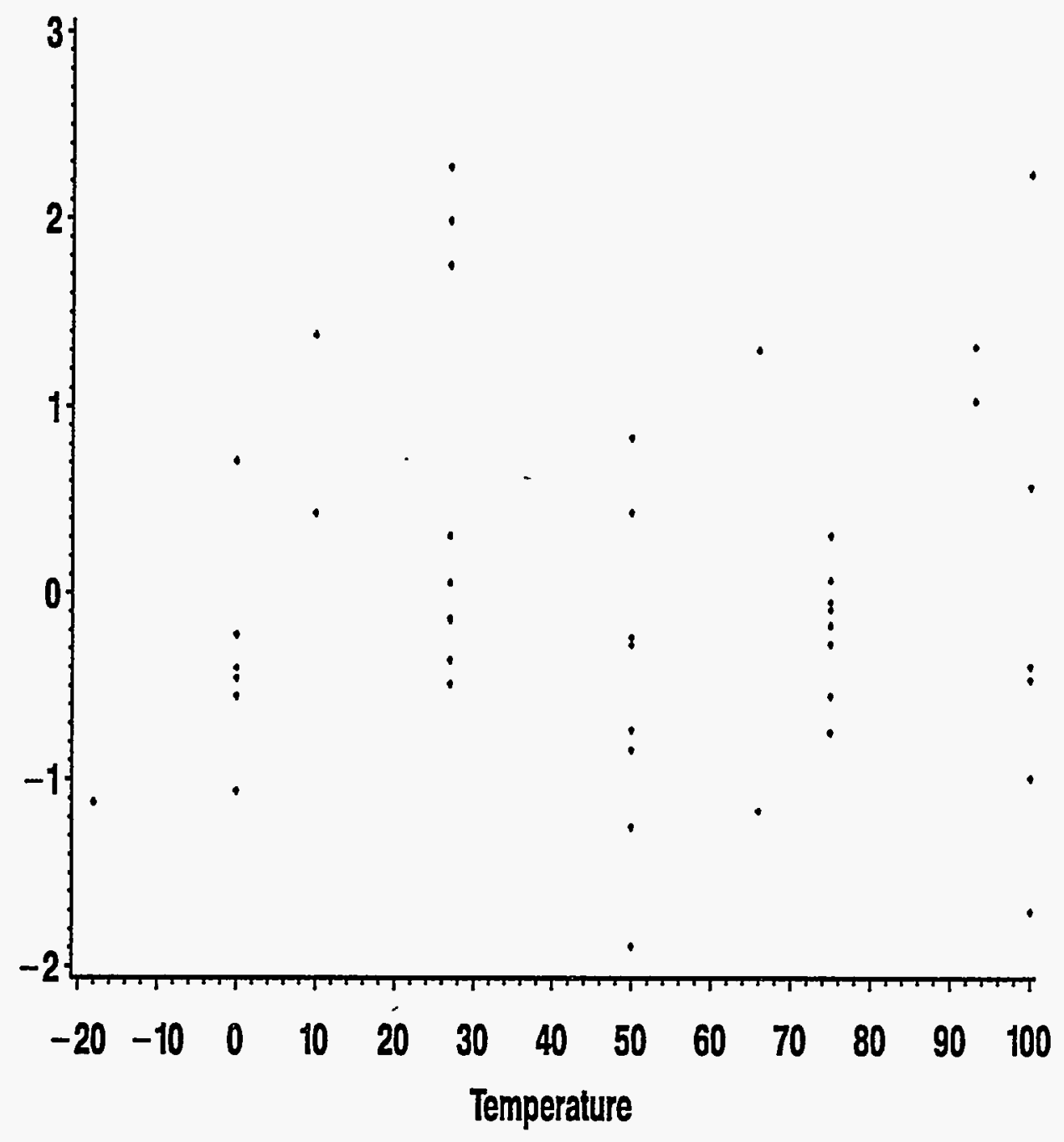

Figure 14: Standardized residuals for the $73 \mathrm{~W}$ irradiated data. Adjusting for error in temperature. 


\section{Standardized}

Residual

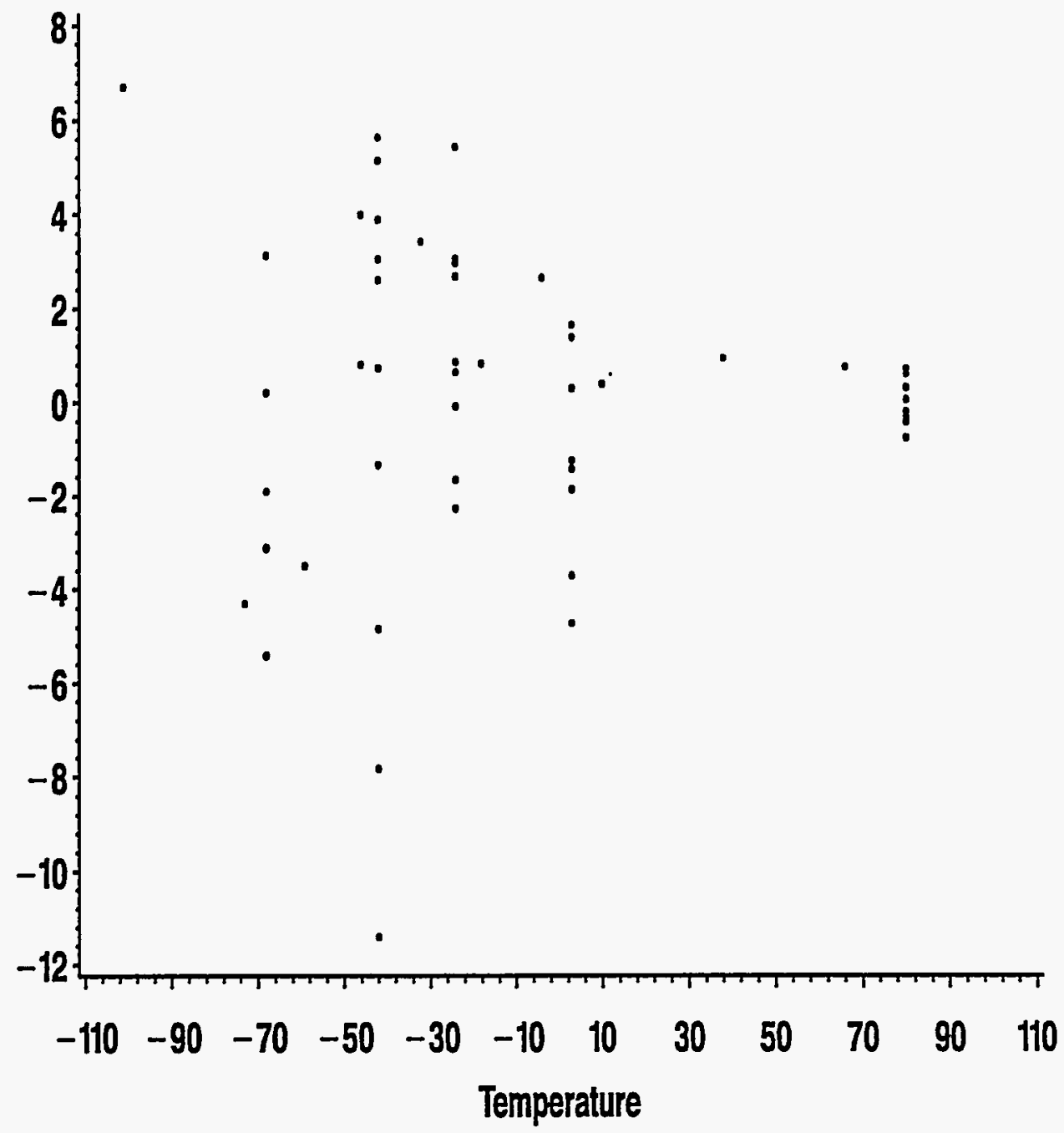

Figure 15: Standardized residuals for $73 \mathrm{~W}$ unirradiated data. Not adjusted for error in temperature. 


\section{Standardized}

Residual

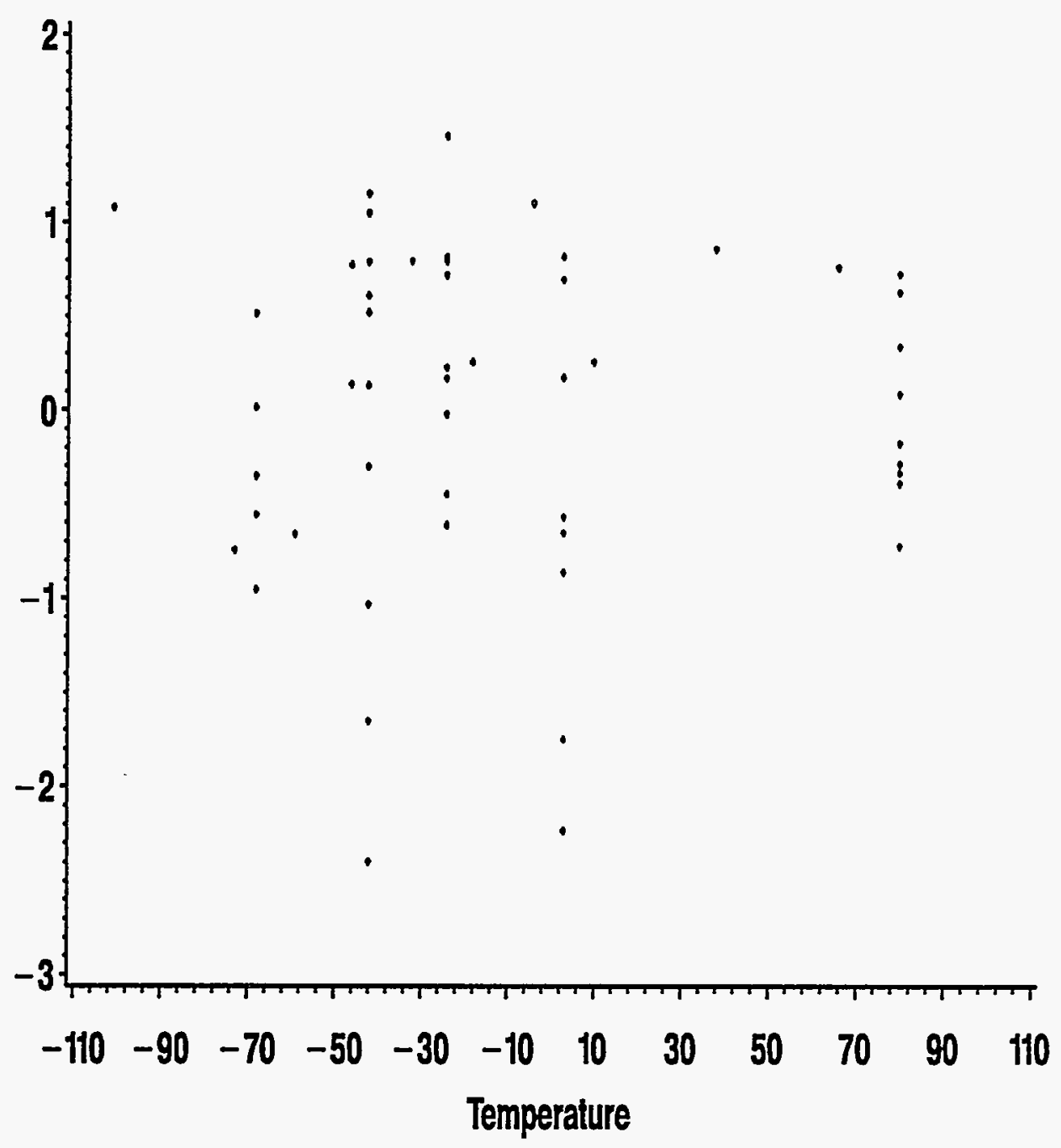

Figure 16: Standardized residuals for the $73 \mathrm{~W}$ unirradiated data. Adjusting for error in temperature. 
cludes $\sigma$ and $\delta$. The corresponding statistical technique for that was considered in a number of publications, and probably the closest regression problems were analyzed in Malyutov, 1982.

Application of the ideas of the iterated estimation to the extended set of unknown parameters: $\theta, \sigma$ and $\delta$ yields the following iterative estimators:

$$
\begin{gathered}
(\hat{\theta}, \hat{\sigma}, \hat{\delta})=\lim _{s \rightarrow \infty}\left(\hat{\theta}_{s}, \hat{\sigma}_{s}, \hat{\delta}_{s}\right), \\
\theta_{s}=\operatorname{Arg} \min _{\theta \in \Omega} \sum_{i=1}^{n} w_{s i}\left[y_{s i}-\eta\left(t_{0 i}, \theta\right)\right]^{2}, \\
\left(\delta_{s}, \sigma_{s}\right)=\operatorname{Arg} \min _{\delta, \sigma} \sum_{i=1}^{n} w_{s i}^{2}\left[u_{s i}-v_{s}\left(t_{0 i}, \sigma, \delta\right)\right]^{2},
\end{gathered}
$$

where

$$
\begin{aligned}
w_{s i}^{-1} & =\sigma_{s-1}^{2}+\delta_{s-1}^{2} \dot{\eta}^{2}\left(t_{0 i}, \theta_{s-1}\right) \\
v_{s}\left(t_{0 i}, \sigma, \delta\right) & =\sigma^{2}+\delta^{2} \dot{\eta}^{2}\left(t_{0 i}, \theta_{s}\right) \\
u_{s i} & =\left[y_{s i}-\eta\left(t_{0 i}, \theta_{s}\right)\right]^{2}
\end{aligned}
$$

From the computational point of view optimization problems (19) and (20) are standard least squares problems. Moreover, (20) is linear. It is evident that (18) - (20) may be replaced by the procedure similar to (12), (13). In our calculations we have used this modified version. We repeated the analysis with the enhanced procedure. Amazingly our initial guesses about $\sigma$ and $\delta$ were very close to the estimated results. Consequently all the results are very close and we do not report the latter ones here.

\section{Conclusions}

1. Heteroscedasticity of residuals may be a consequence of not being able 
to control independent variables as well as we think. The effect is more pronounced in areas for which the response function has greater slope.

2. Results of using the usual least squares estimators make us think that we are doing better than we are, i.e. the standardly reported "accuracy" measures are not true. When the curvature of the response function is significant the usual least squares estimators are not consistent and may show a noticeable bias even for moderate sample sizes.

3. Methods are proposed to estimate all parameters including variances of errors both in response and predictors. These methods allow one to develop algorithms based on software available through commercial packages (SAS, for instance was used in this study). 


\section{References}

[1] Downing, D. J., Haggag, F. M. and Nanstad, R. K. (1990), "Estimating Charpy Transition Temperature Shift Using Weibull Analysis", Int. J. Pres. Ves. and Piping, 44, 241-254.

[2] Charnes, A., Frome, E. L., and Yu, P. L. (1976), "The Equivalence of Least Squares and Maximum Likelihood Estimates in the Exponential Family", JASA, 71, 216-222.

[3] Fedorov, V. V. (1974), "Regression Problems with controllable Variables Subject to Error", Biometrika, 61, 49-56.

[4] Helm, J. L. (1995), "The Interpretation of Charpy Impact Test Data Using Hyper-Logistic Fitting Functions", in Effects of Radiation on Materials: 17th International symposium, ASTM STP 12xx, Gelles, D. S., Nanstad, R. K., Kumar, A. S., and Little, E. H., Editors, American Society for Testing and Materials, Philadelphia.

[5] Jennrich, R. I., and Moore, R. H. (1975) "Maximum Likelihood Estimation by Means of Nonlinear Least Squares", Am. Stat. Assoc., Proc. Statist. Comput. Section, 57-65.

[6] Malyutov, M. B. (1982), "Asymptotical Properties and Applications of the IRGINA-estimator of Parameters of Generalized Regression Model", in Stochastic Processes and Applications, Moscow, pp. 144-158.

[7] Seber, G. A. F., and Wild, C. T. (1989), Nonlinear Regression, Wiley, New York.

[8] Fuller, W. A. (1987), Measurement Error Models, Wiley, New York.

[9] SAS (1990) Version 6, Fourth Edition, Cary, North Carolina. 


\section{INTERNAL DISTRIBUTION}

1. D. J. Alexander

2. C. K. Bayne

3. W. R. Corwin

4. D. F. Craig

5. T. S. Darland

6. C.S. Daw

- 7-11. D. J. Downing

12. L. J. Gray

13. H. W. Hayden, Jr.

14. S. K. Iskander

15. P. Kanciruk

16-20. W. F. Lawkins

21-25. M. R. Leuze

26. D. E. McCabe

27. J. G. Merkle

28-32. M. D. Morris
33. R. K. Nanstad

34. C. E. Oliver

35-39. G. Ostrouchov

40-44. S. A. Raby

45. R. L. Schmoyer

46. R. F. Sincovec

47. P. T. Singley

48. M. A. Sokolov

49. D. A. Wolf

50. K-25 Applied Tech. Library

51. Y-12 Technical Library

52. Laboratory Records - RC

53-54. Laboratory Records Dept.

55. Central Research Library

56. M\&C Records Office

57. ORNL Patent Office

\section{EXTERNAL DISTRIBUTION}

58. Dr. Richard Beckman, Statistics Group Al, Los Alamos National Laboratory, MS F600, Los Alamos, NM 87545

59. C. Bolton, Nuclear Electric, Berkeley Nuclear Laboratories, Berkeley, Gloucestershire, GL139PB, United Kingdom

60. Prof. Dennis Cox, Department of Statistics, Rice University, Houston, TX 772511892

61. E. Eason, Modeling and Computing Services, Suite 105, 6400 Lookout Road, Boulder, CO 80301

62. Prof. Sherwood Ebey, Department of Mathematics, University of the South, Sewanee, TN 37375

63. A. Fabry, Central Institute for Nuclear Studies, SCK-CEN, Boeretang 200, B $2400 \mathrm{Mol}$, Belgium

64. Dr. David Hall, Statistics, Systems Department, Pacific Northwest Laboratory, P.O. Box 999, Richland, WA 99352

65. Prof. J. A. Hartigan, Department of Statistics, Yale University, Box 2179 - Yale Station, New Haven, CT 06520

66. J. Helm, Department of Applied Physics, 202 Mudd Building, Columbia University, New York, NY 10027 
67. Dr. Dan Hitchcock, Office of Scientific Computing, ER-7, Applied Mathematical Sciences, Office of Energy Research, U. S. Department of Energy, Washington, DC 20585

68. Dr. Fred Howes, Office of Scientific COmputing, ER-7, Applied Mathematical Sciences, Office of Energy Research, U. S. Department of Energy, Washington, DC 20585

69. Prof. Mark Johnson, Department of Statistics, University of Central Flordia, Orlando, FL 32816-0370

70. Dr. A. M. Liebetrau, Computational Sciences Department, Battelle-Northwest, P. O. Box 999, Richland, WA 99352

71. Dr. J. Lijengren, Pacific Northwest Laboratories, P. O. Box 999, Richland, WA 99352

72. R. McElroy, AEA Technology, Harwell Laboratory, Oxfordshire OX11 ORA, United Kingdom

73. Dr. Michael McKay, Statistics Group Al, Los Alamos National Laboratory, MS F600, Los Alamos, NM 87545

74. Prof. Lisa Moore, Institute of Statistics and Decision Sciences, Duke University, Durham, NC 27706

75. Dr. David Nelson, Director of Scientific Computing, ER-7, Applied Mathematical Sciences, Office of Energy Research, U. S. Department of Energy, Washington, DC 20585

76. G. R. Odette, Department of Chemical and Nuclear Engineering, Ward Memorial Drive, University of California, Santa Barbara, A 93106

77. Dr. David J. Pack, CSR Institute, 8889 Bourgade AV, Lenaxa, KS 66219

78. Mr. Brent Pulsipher, Computational Sciences Department, Battelle Northwest, P. O. Box 999 , K1-86, Richland, WA 99352

79. Dr. Jerome Sacks, NISS, P. O. Box 14162, Research Triangle Park, NC 277094162

80. Prof. A. F. Smith, Department of Mathematics, University of Nottingham, University Park, Nottingham NG7 2RD, England

81. Dr. Alan Solomon, P. O. Box 227, Omer 84965, Israel

82. Dr. Daniel L. Solomon, Department of Statistics, North Carolina State University, P. O. Box 5457, Raleigh, NC 27650

83. A. Taboada, Mail Stop T0-E10, Division of Engineering, U.S. Nuclear Regulatory Commission, Washington, DC 20555

84. M. G. Vassilaros, MS T10-E10, Division of Engineering, U. S. Nuclear Regulatory Commission, Washington, DC 20555

85. K. Wallin, Senior Consultant, Technical Research Centre of Finalnd, Kemistintie 3, Box 2G, Espoo 02750, Finland

86. Prof. William Welch, Department of Statistics and Acturial Science, University of Waterloo, Waterloo, Ontario N2L 3G1, Canada 
87. Prof. Y. C. Yao, Department of Statistics, Colorado State University, Fort Collins, CO 80523

88. Prof. Don Ylvisaker, Department of Mathematics, University of California, Los Angeles, CA 90024

89. Office of Assistant Manager for Energy Research and Development, Deaprtment of Energy, Oak Ridge Operations Office, P. O. Box 2001, Oak Ridge, TN 37831-8600

90. Office of Scientific and Technical Information, P. O. Box 62, Oak Ridge, TN 37830 


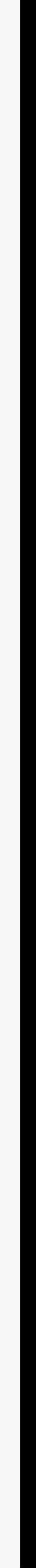

